\title{
Structural and Optical Properties of Chemically Sprayed ZnS Nanostructure
}

\author{
Zainab J. Shanan, H.F.Al-Taay, Nisreen khaleel, Rajaa Nader, \\ Eman kaddum, Sara Talal \\ College of science for Women, University of Baghdad, Jadriya, Baghdad, Iraq
}

\begin{abstract}
Zinc Sulfide nanostructure was successfully deposited on glass substrates by spray pyrolysis method. The films were grown at substrate temperatures in $300^{\circ} \mathrm{C}$. The structural and optical properties were studied. The XRD profiles showed that the films are polycrystalline with cubic structure grown preferentially along the (111) axis. Atomic force microscopy shows that the grain size for film was $38.78 \mathrm{~nm}$. The optical studies exhibit direct allowed transition. Energy band gap was $4.0 \mathrm{eV}$. The refractive index was estimated within the visible wavelength at $500 \mathrm{~nm}$, it was 1.238. The photoluminescence spectra of the powder showed two peaks centered on $360 \mathrm{~nm}$ and $485 \mathrm{~nm}$.
\end{abstract}

Keywords: ZnS films, Spray pyrolysis, Substrate temperature, XRD, and Optical properties

\section{Introduction}

Zinc sulphide belongs to II-VI group compound material with large direct band gap between 3.4 - 3.70 $\mathrm{eV}$ depending upon composition. It is potentially important material to be used as an antireflecting coating for heterojunction solar cells [1], for light emitting diode [2, 3], and other optoelectronic devices such as blue light emitting diode [4], electro luminescence devices and photovoltaic cells which enable wide application in the field of displays [5, 6], sensor and Laser [7], In recent years $\mathrm{ZnS}$ attracted much attention because the properties in nano form differ significantly from those of their bulk counter parts. Therefore much effort has been made to control the size, morphology and crystalline of $\mathrm{ZnS}$ thin films. There has been growing interest in developing techniques for preparing semi conductor nano particles and films.

$\mathrm{ZnS}$ thin films can be obtained a variety of techniques RF sputtering [8], Chemical vapor deposition [9], Spray Pyrolysis [10], atomic layer deposition [11] and chemical bath depositions [12-15]. In present investigation $\mathrm{ZnS}$ thin films have been deposited using Chemical Spray Pyrolysis techniques. The optical and structural properties of the as deposited $\mathrm{ZnS}$ nanontructure were studied.

\section{Experimental Details}

Thin films of ZnS are prepared by spray pyrolysis with air as atmosphere. Spray pyrolysis is basically a chemical deposition technique in which fine droplets of the desired material solution was sprayed onto a heated substrate. The initial solution was prepared with one part $0.1 \mathrm{M} \mathrm{ZnCl}_{2}$ and one part $0.1 \mathrm{M} \mathrm{SC}\left(\mathrm{NH}_{2}\right)_{2}$ [thiourea] in deionized water. Other salts of zinc such as $\mathrm{ZnSO}_{4}, \mathrm{ZnCl}_{2}, \mathrm{Zn}\left(\mathrm{NO}_{3}\right)_{2}$, etc., can be used for deposition. A glass substrate $\left(2 \times 2 \times 0.1 \mathrm{~cm}^{3}\right)$ was used for the preparation of $\mathrm{ZnS}$. The spray time was 30 minutes and pressure was $0.2 \mathrm{~kg} / \mathrm{cm} 3$. The substrate temperature was $300^{\circ} \mathrm{C}$. The structural study was carried out using X-ray diffractometer with nickel filtered monochromated $\mathrm{CuK} \alpha$ radiation $(\lambda=1.5405 \AA)$. The optical transmittance was recorded using a UV-VIS- Spectrophotometer SP-3000 plus, OPTIMA INC. Japan, in the wavelength range 200-1000 nm. The PL spectrum of the ZnS has been measured at room temperature using Hitachi F-2500 FL Spectro-photometer. In order to investigate the surface morphology and surface roughness, the atomic force microscopy (AFM) observations were performed using an an SPM model AA 3000, Angstrom Advanced Ins.,USA . The AFM images were analyzed with the Pro Scan software (Park Scientific Instruments), calculating the root mean square surface roughness value.

\subsection{Structural Studies}

\section{Results And Discussion}

The XRD patterns of the sample are given in (Figures 1). The most significant feature within the observed pattern, at $2 \theta=29.43$, is assigned to the (111) reflection of the cubic zinc blende structure of $\mathrm{ZnS}$ (JCPDS No 5-566) .Two other prominent features are observed at $2 \theta=47.59$ and 57.51, which belong to (220) and (311) reflections. No peaks from any other impurities such as $\mathrm{ZnO}$ or other compounds are detected. Our results are agreed with $[16,17]$.

From the x-ray patterns the broadening of the diffraction peaks of the nanoparticles is obvious [18, 19] which is characteristic of nanosized by applying Debye- scherrer formula [20]. 
$\mathrm{D}=\frac{0.9 \lambda}{\beta \cos \theta}$

Where $k$ denotes the Scherrer constant (the shape factor of the average crystallite and can be considered $\mathrm{k}=0.90, \lambda=1.5418 \AA$ is the wavelength of the incident $\mathrm{Cu} \mathrm{K} \alpha$ radiation, $\Theta$ is the Bragg diffraction angle, and $\beta$ is the FWHM of the XRD peak appearing at the diffraction angle $\Theta$.

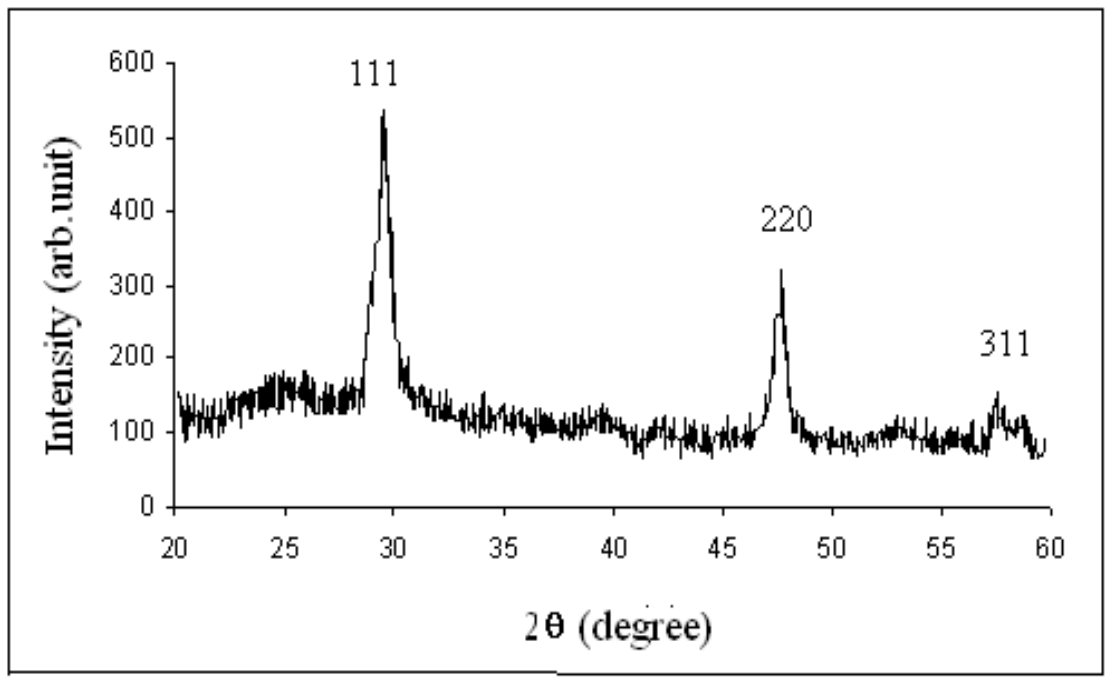

Figure 1: X-ray diffraction patterns of the $\mathrm{ZnS}$ nanostructure

The average crystalline sizes were calculated from X-ray line broadening using (111), (220) and (311) peaks and Debye-Scherrer equation and tabulated in Table 1. The calculated values of $\mathrm{D}$ give an indication that the size lie within the nanostructure range. As shown in Table 1 , larger D of $28 \mathrm{~nm}$ and smaller $\beta$ of $5.11 \times 10^{-3}$ $\mathrm{nm}^{-2}$ values of preferential orientation along (111) direction indicate better crystallization of the material [21].

Additionally, to have more information on the amount of defects in the film, the dislocation density $(\delta)$ was evaluated from the formula [22]:

$$
\delta=\frac{1}{D^{2}}
$$

where $\mathrm{D}$ is the grain size. This quantity, $\delta$, is defined as the number of dislocations intersecting a unit area of a random section. It is seen from Table 1 that the $\delta$ value of the preferential orientation of the XRD peaks along (111) direction is smaller than the other peaks.

Table 1: The diffraction angle (2Ө), FWHM $(\beta)$, the grain size (D), the dislocation density $(\delta)$, of the prepared $\mathrm{ZnS}$ nanostructure

\begin{tabular}{|l|l|l|l|l|}
\hline $\begin{array}{l}\text { Identification with } \\
(\mathrm{hkl}) \text { values }\end{array}$ & $2 \theta$ (degree) & $\begin{array}{l}\beta \times 10^{-3} \\
(\mathrm{rad})\end{array}$ & $\begin{array}{l}\mathrm{D} \\
(\mathrm{nm})\end{array}$ & $\begin{array}{l}\delta \times 10^{-3} \\
\left(\mathrm{~nm}^{-2}\right)\end{array}$ \\
\hline$(111)$ & 29.43 & 5.11 & 28.00 & 1.27 \\
\hline$(220)$ & 47.59 & 5.49 & 27.56 & 1.31 \\
\hline$(311)$ & 57.51 & 7.08 & 22.33 & 2.00 \\
\hline
\end{tabular}

\subsection{Surface Morphology}

Atomic Force Microscopy (AFM) is a surface analytical technique used to capture high resolution images of a surface to get microscopic information on the surface structure and to plot topographies representing the surface relief. AFM studies were carried out to evaluate the grain size and surface roughness of $\mathrm{ZnS}$ thin films. AFM images of $\mathrm{ZnS}$ film are shown in Figure 2 for two and three dimensions and figure 3 its distribution chart. 

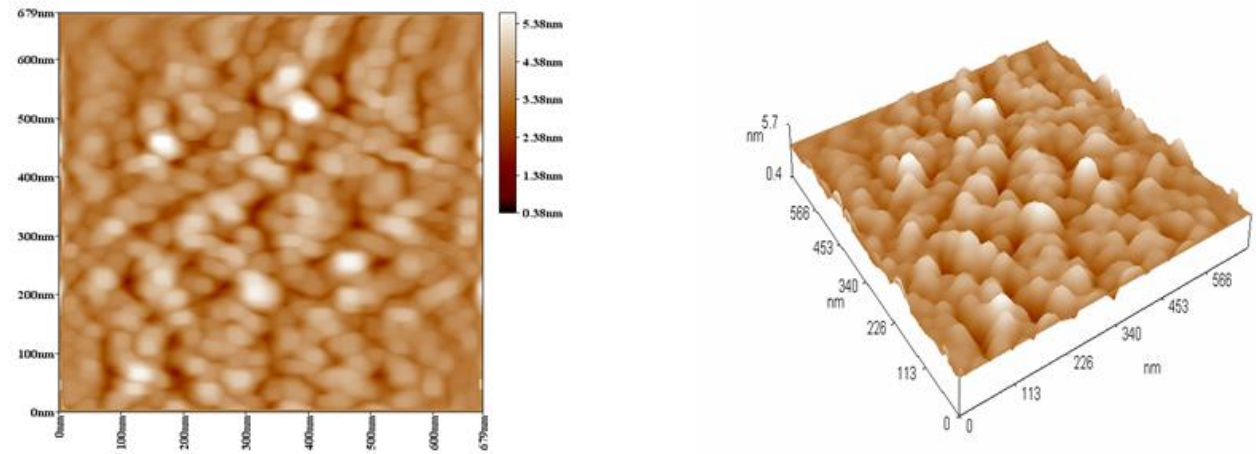

Figure 2: AFM images of $\mathrm{ZnS}$ nanostructure for two and three dimensional

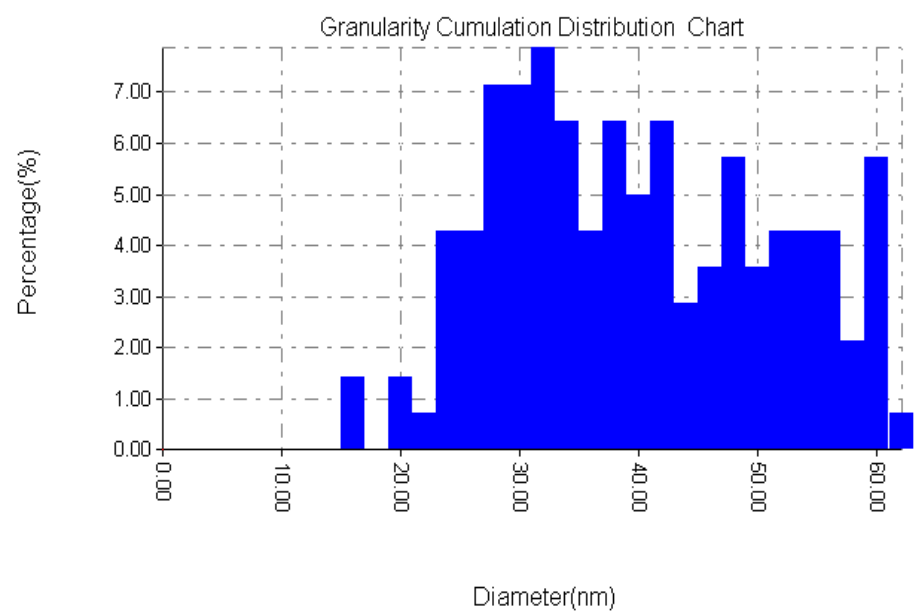

Figure 3: Mean particle size and particle distribution

The thin film as observable in the images is made of aggregates (clusters) with a spherical shaped grain. The calculated root mean square roughness $\left(\mathrm{R}_{\mathrm{q}}\right)$ and average roughness $\left(\mathrm{R}_{\mathrm{a}}\right)$ of the film were found to be $0.516 \mathrm{~nm}$ and $0.39 \mathrm{~nm}$, respectively. The roughness of the films is unavoidable since the grains are spherical in shape and various sizes [23]. The calculated average grain size was found to be $38.78 \mathrm{~nm}$ in diameter. Its result agreed with x-ray diffraction study according of grain size.

\subsection{Optical Properties}

The optical properties of $\mathrm{ZnS}$ nanostructure is determined from absorbance measurement in the range $300-1100 \mathrm{~nm}$ (see Figures 4) show the absorption spectra. Absorbance coefficient $\alpha$ associated the strong absorption region of the film was calculated from absorbance (A) and the film thickness ( $\mathrm{t}$ ) using relation [24, 25]

$\alpha=2.3026 \mathrm{~A} / \mathrm{t}$

where the thickness of film was $112 \mathrm{~nm}$.

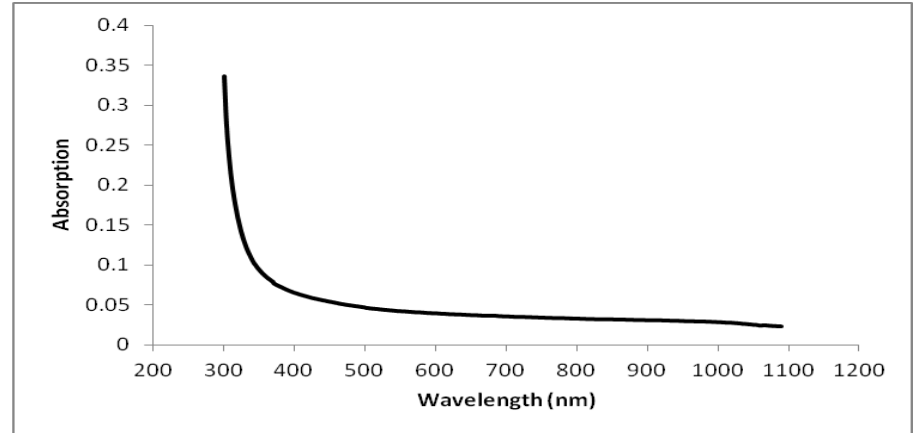

Figure 4: UV-Vis absorption spectra of $\mathrm{ZnS}$ nanostructure 
The absorption coefficient $\alpha$ was analyzed using the following expression for optical absorption of semiconductors [26]

$(\alpha h v)=A(h v-E g)^{n / 2}$

Where A is constant, Eg is separation between valence and conduction bands and $\mathrm{n}$ is constant that is equal to 1 for direct band gap semiconductor

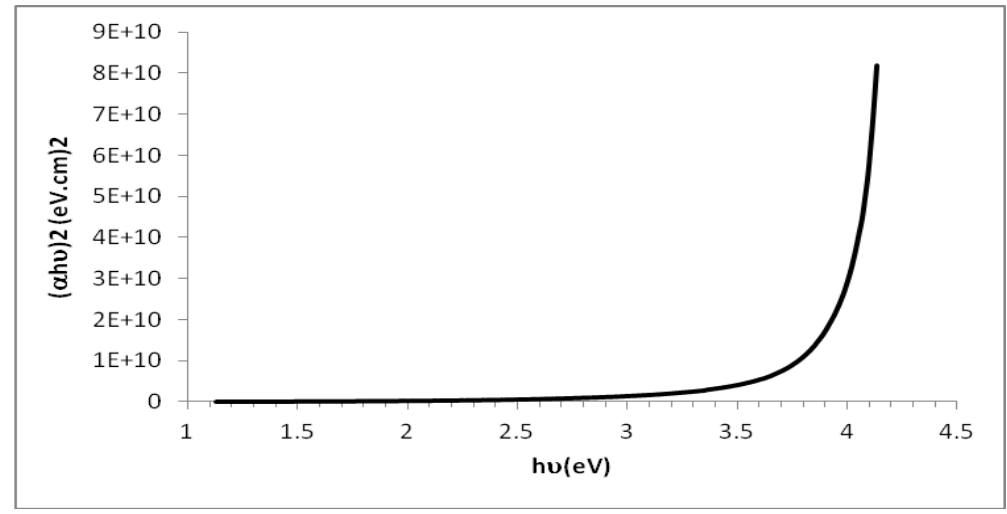

Figure 5: Band gap of $\mathrm{ZnS}$ nanostructure

The band gap values were determined from the intercept of the straight-line portion of the ( $\square \mathrm{h} \square)^{2}$ against the $\mathrm{h} \square$ graph on the $\mathrm{h} \square$-axis using computer fitting program (Fig. 5). The linear part shows that the mode of transition in these films is of direct nature. The calculated band-gap value of the film was $\sim 4.0 \mathrm{eV}$. The band-gap values are higher than bulk value of $\mathrm{ZnS}(3.68 \mathrm{eV})$ because of quantum confinement of $\mathrm{ZnS}$ nanostructure. The absorption spectra (Fig.4) reveal that the excitonic absorption peaks for nanostructurel is blue shifted compared to the bulk band gap ( $3.68 \mathrm{eV}$ corresponding to the absorption edge at $336 \mathrm{~nm}$ ) and clearly indicate strong quantum size effect.

(Fig. 6) show the transmission spectra of $\mathrm{ZnS}$ nanostructure. It can be observed that above the $400 \mathrm{~nm}$ wavelength the transmittance increased to about $80 \%$, which makes it a good material for optoelectronic devices as a window layer.

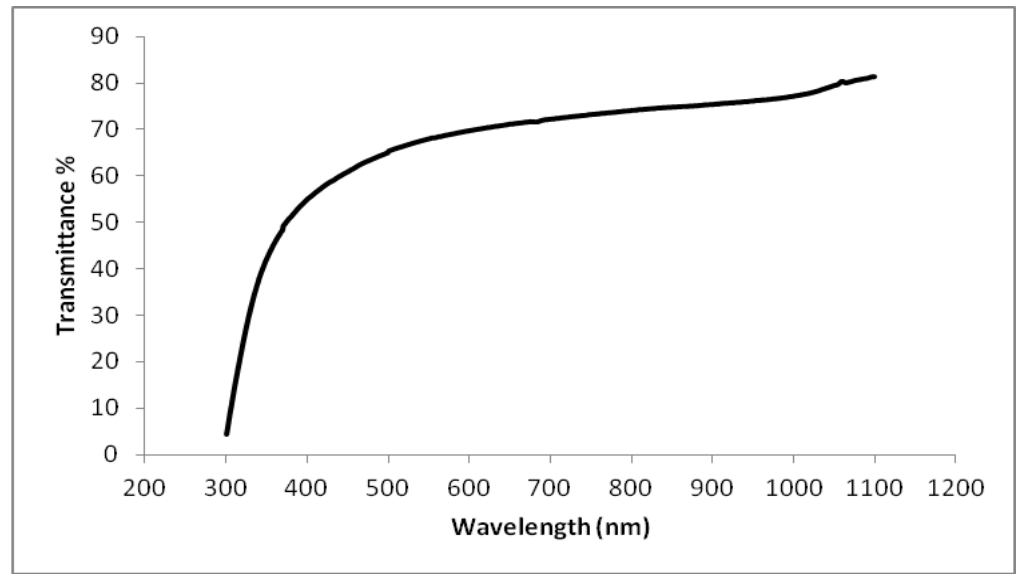

Figure 6: The transmission spectra of $\mathrm{ZnS}$ nanostructure

\section{4 optical constant}

\subsubsection{Extinction Coefficient}

The extinction coefficient $(\mathrm{k})$ can be determined from the absorbance measurements as a function of the wavelength within the range $300-1100 \mathrm{~nm}$; it was calculated by using the following equation:

$k=\alpha \lambda / 4 \pi$

where $\lambda$ is the wavelength. Extinction coefficient versus wavelength spectra is shown in (Fig. 7), there is a little changing in the extinction coefficient in the visible range; $(400-1100) \mathrm{nm}$, then the rapid rise appeared within the range $300-400 \mathrm{~nm}$. 


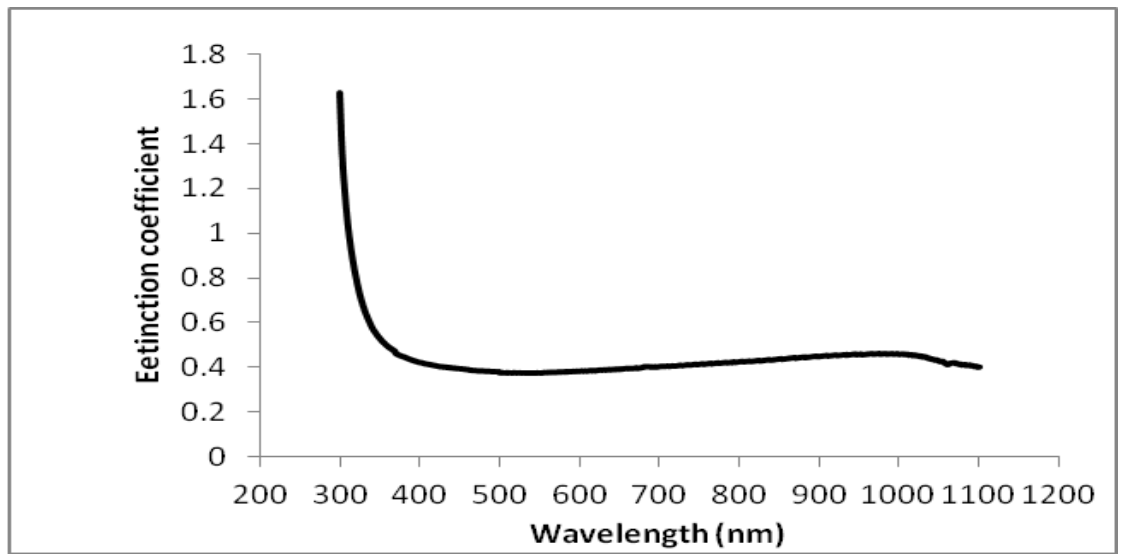

Fig. 7: The extinction coefficient of $\mathrm{ZnS}$ nanostructure

\subsubsection{Refractive index}

The refractive index of material is the key parameter for device design. In semiconductor the evaluation of refractive index is of considerable importance for applications in integrated optics [27]. The refractive index (n) was determined from a transmittance spectrum as a function of the photon energy within the wavelength in the range $300-1100 \mathrm{~nm}$. The refractive index (n) can be determined by using equation

$\mathrm{n}=[(4 \mathrm{R} /(\mathrm{R}-1) 2)-\mathrm{K} 2] 1 / 2-[(\mathrm{R}+1) /(\mathrm{R}-1)]$

The refractive index of the prepared film was calculated in the visible region, it was $\sim 1.238$ at wavelength $500 \mathrm{~nm}$, as shown in (Fig. 8).

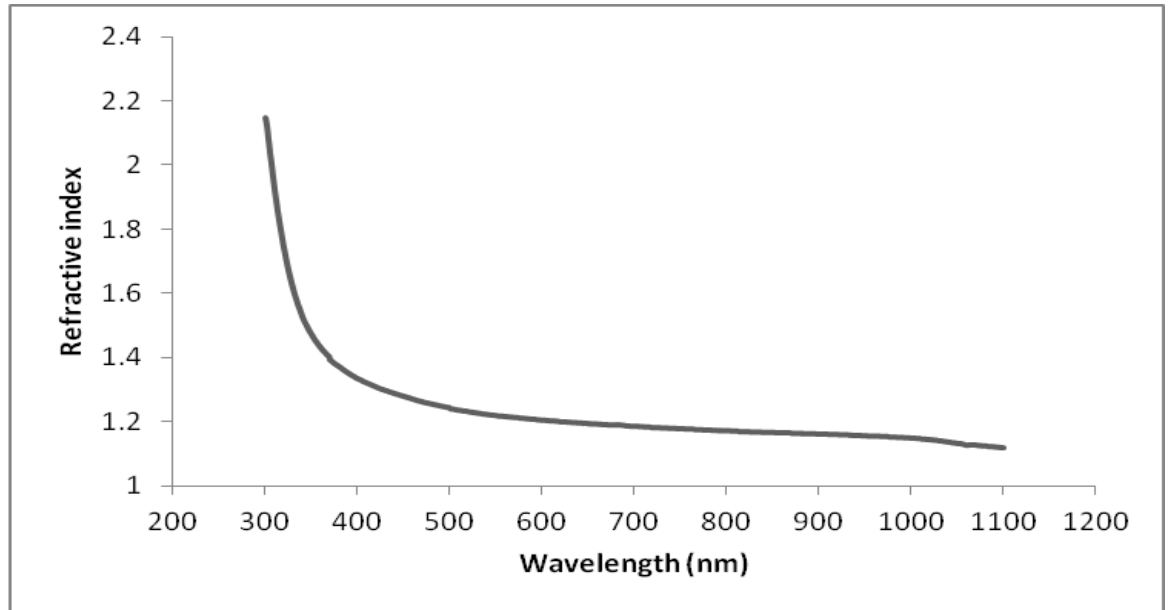

Figure 8: The refractive index of $\mathrm{ZnS}$ nanostructure

\subsubsection{The Dielectric Constant}

The real parts of dielectric constant $\left(\varepsilon_{\mathrm{r}}\right)$ can be calculated from the relation:

$\varepsilon_{\mathrm{r}}=\mathrm{n}^{2}-\mathrm{k}^{2}$

The imaginary parts of dielectric constant $(\varepsilon$ i) can be calculated from the relation

$\varepsilon_{\mathrm{i}}=2 \mathrm{nk}$

Where $\mathrm{n}$ is representing as the refractive index, $\mathrm{k}$ is the extinction coefficient. (Fig. 9) show the plot $\varepsilon \mathrm{i}$ against the wavelength. From the (Fig.9) we can observe that the real part of dielectric constant decreases with increasing $(\lambda)$. This behavior is similar to the behavior of the refractive index. (Fig.10) show the imaginary part of dielectric constant for prepared film. 


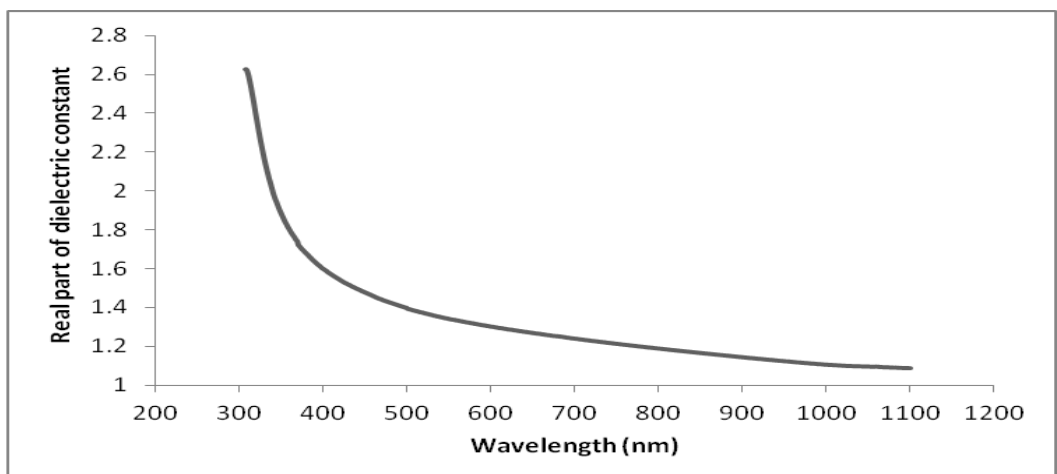

Figure 9: The real parts of dielectric constant for $\mathrm{ZnS}$ nanostructure

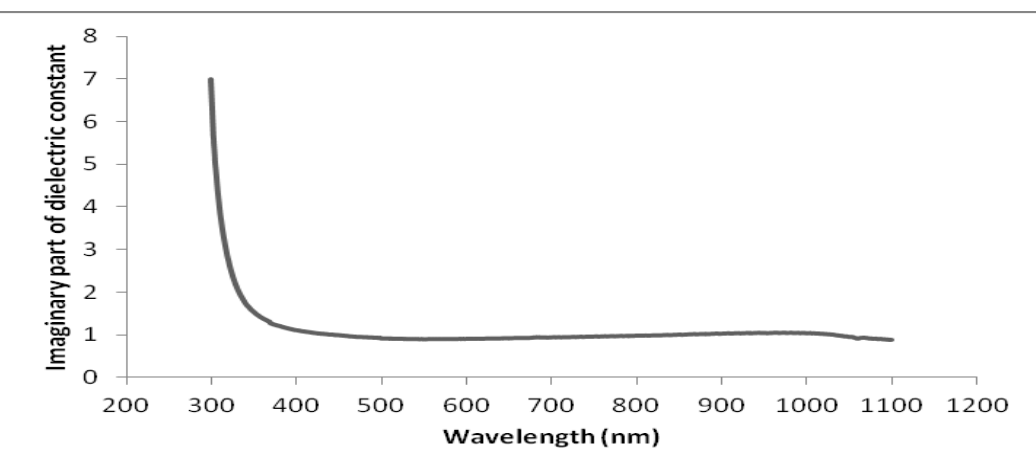

Figure 10: The imaginary parts of dielectric constant for $\mathrm{ZnS}$ nanostructure

\subsection{Photoluminescence Study}

PL measurements then yielded information about band gap energies of nanostructures that can be tuned by varying their sizes and the energetic positions of the electronic states in the band gap. On the other hand, wide band gap semiconductors are ideal materials for studies on trap states. Such localized states can be due to various types of imperfections like vacancies, interstitial atoms and dangling bonds. Bulk $\mathrm{ZnS}$ has a wide direct band gap of $3.68 \mathrm{eV}$. The large exciton binding energy $(40 \mathrm{meV})$ is much higher than thermal energy at room temperature $(\sim 26 \mathrm{meV})$, the band edge PL of $\mathrm{ZnS}$ at room temperature is observed in high quality crystal [28]. The photoluminescence spectrum measured of $\mathrm{ZnS}$ nanocrystalline thin films deposited on glass substrate as shown in (Fig.11).In figure show that two peaks positioned are around $360 \mathrm{~nm}$ and $485 \mathrm{~nm}$. Usually for semiconductor nanocrystals, two emission peaks can be observed, the exciton and the trapped luminescence .The exciton emission peak is sharp and the trapped emission is broad [29]. The emission bands showed in the spectra can be attributed to band gap emission and the strong band gap emission demonstrates the high crystalline nature of the as-synthesized particles. The emission at $485 \mathrm{~nm}$ may be caused by the transition from the conduction band to the zinc vacancies $\mathrm{V}_{\mathrm{Zn}}$ level (this localized vacancy level is above the valence band at $1.1 \mathrm{eV}$ ). The peaks at $360 \mathrm{~nm}$ can indicate exciton recombination [28] .Our results are agreed with [30].

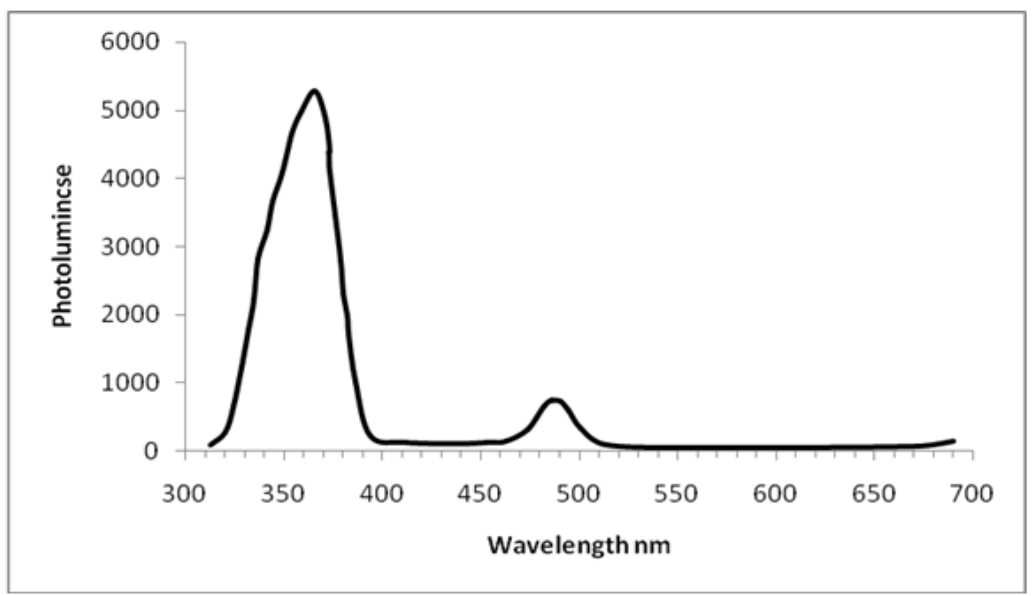

Figure 11: Photoluminescence spectra of $\mathrm{ZnS}$ nanostructure 


\section{Conclusions}

Zinc sulfide nanostructure thin films were deposited onto glass substrate by using spray pyrolysis method. The structural, morphological and optical properties of the coated film were studied. XRD shows that the as deposited film is polycrystalline in nature and has a cubic crystal structure with the preferred plane of $\mathrm{ZnS}$ (111). The crystallite size of ambient deposited $\mathrm{ZnS}$ waveguide for this particular plane is about $28 \mathrm{~nm}$. AFM micrograph reveals that substrate is well covered with spherical shaped grain and average grain size of 38.78 $\mathrm{nm}$. The prepared films have wide direct energy gap, the wide band gap makes these films good material for optoelectronic devices such as a window layer in photovoltaic cells. PL measurement at room temperature showed that the two peaks positioned are around of $360 \mathrm{~nm}$ and $485 \mathrm{~nm}$.

\section{References}

[1] W.H. Bloss, F. Plisterer, H.W. Schock "Advances in Solar energy, and Annual review of research \& development”, 1988, Vol. 4, P275

[2] H. Katayama, S. Oda, H. Kukimoto, Appl. Phys. Lett., 1975, 27, 657

[3] A. Antony, K.V. Mirali, R. Manoj, M.K. Jayaraj, Mater. Chem. Phys., 2005, 90, 106.

[4] S. Coe, W.K. Woo, M.G. Bawendi, V. Bulovic, Nature, 2002, 420, 800

[5] N. Habubi, M. Hashim and A. Al-Yasiri, Baghdad Science Journal, 7 (2010) 1421

[6] R.P. Raffaelle, S. L. Castro, A.F. Hepp, S.G. Bailey, Prog. Photovoltaic, 2002, 10, 433

[7] V.I. Klimov, A.A. Mikhailovsky, S. Xu, A. Malko, J.A. Hollingsworth, C.A. Leatherdale, H.J. Eisler, M.G. Bavendi, Science, 2000, $290,314$.

[8] O.L. Arenas, M.T.S. Nair, P.K. Nair, Semicond. Sci. Technol. 12, 1323 (1997).

[9] J.M. Blacmore, A.G. Cullis, Thin, Solid Films 199, 321 (1991)

[10] J.W. Li, Y.K. Su, M. Yokoyama, Jpn. J. Appl. Phys. 33, 4723 (1994).

[11] N. Tohge, S. Tamaki, K. Okuyama, Jpn. J. Appl. Phys. 34, L 207 (1995).

[12] J.M. Dona, J. Herrero, Thin Solid Films 268, 5 (1995).

[13] J. Vidal, O. de Melo, O. Vigil, N. Lopez, G. Contreras- Puente, O. Zelaya-Angel., Thin Solid Films 419, 188 (2002).

[14] A. Antony, K.V. Mirali, R. Manoj, M.K. Jayaraj, Meter. Chem. And Phys. 90, 106 (2005)

[15] Q. Liu, M. Guobing, A. Jianping, Appl. Surf. Sci. 254, 5711 (2008).

[16] M. S.Niasari, M. Ranjbar, D. Ghanbari, Journal of nanostructure, 1 (2012) 231-235.

[17] X. Zhang, H.Song_, L. Yu, T. Wang, X. Ren, X. Kong, Y.Xie and X.Wang, Journal of Luminescence, 118, (2006) 251-256.

[18] Large area electro-optical tactile sensor: Characterization and design of a polymer, nanoparticle based tunneling device David Cox, (2006).

[19] J. Zhu, M . Zhou, J .Xu, X. Liao ,Materials Lett. 47, (2001), 25-29.

[20] R.John, S.Sasiflrence, Chalcogenide Lett. 7 (2010), 269-273.

[21] N.F. Habubi1, R.A. Al-Anssari and J.A. Abd, 2013. Nano Science and Nano Technology, 7(5): 172-178.

[22] W.D. Callister, 1997. "Materials Science and Engineering - An Introduction". New York, John Wiley and Sons.

[23] A. Kassim, N. Razak, and H.Min, 2011. International Journal of Advanced Engineering Sciences and Technologies, 7(1): 169-172.

[24] R.S. Longhurst, 1957. Geometrical and Physical Optics, Longmans Green, London.

[25] A. cottrell, 1975. Intorduction to Mettallurgy ,Arnold, Londan, P.173.

[26] J. Bo, P. rah, and K.C. Sarma, 2008." Optical and Optoelectronic Properties of ZnS Nanostructured Thin Film", ACTA PHYSICA POLONICA A, 114 (2008) 713-719.

[27] T.S. Moss, 1986. "Infrared Physics" 26, 5, (1986) 335-336.

[28] N. Üzar, and M. Arikan, 2011. "Synthesis and investigation of optical properties of ZnS nanostructures", Bull. Mater. Sci., 34, (2011), 287-292.

[29] R. John, S. Florence, 2010. "Optical, structural and morphological studies of beanlike ZnS nanostructures by aqueous chemical method", Chalcogenide Letters , 7(2010). $269-273$.

[30] D. Kurbatov, A. Opan, S. Kshnyakina, V. Melnik, and V. Nesprava, 2010. "Luminescent and optical characteristics of zinc sulfide thin filoms produced by close-spaced vacuum sublimation", Rom. Journ. Phys., 55(2010) 213-219. 